\title{
ChemComm
}

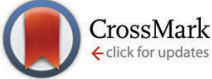

Cite this: Chem. Commun., 2015, 51,3870

Received 4th January 2015

Accepted 28th January 2015

DOI: $10.1039 / \mathrm{c} 5 \mathrm{cc00052a}$

www.rsc.org/chemcomm

\section{Amino acids as chiral anionic ligands for ruthenium based asymmetric olefin metathesis $\dagger$}

\author{
Elisa Ivry, ${ }^{a}$ Amos Ben-Asuly, ${ }^{a}$ Israel Goldberg ${ }^{b}$ and N. Gabriel Lemcoff ${ }^{\star^{a}}$
}

\begin{abstract}
Several amino acid ligands were introduced into the Hoveyda-Grubbs 2nd generation complex by a facile anionic ligand exchange. The chiral pre-catalysts obtained displayed enantioselectivity in asymmetric ringclosing and ring-opening cross-metathesis reactions. Reduction of the lability of the carboxylate ligands was found to be cardinal for improving the observed enantiomeric product enrichment.
\end{abstract}

Since its universal recognition in $2005,{ }^{1}$ the field of olefin metathesis in organic synthesis ${ }^{2}$ has continued its phenomenal development in many aspects, such as: $Z$-selectivity, ${ }^{3}$ latency, ${ }^{4}$ synthesis of sterically hindered alkenes, ${ }^{5}$ aqueous based metathesis, ${ }^{6}$ etc. Asymmetric olefin metathesis, as in ACM (asymmetric cross metathesis), ARCM (asymmetric ring closing metathesis) and AROCM (asymmetric ring opening cross metathesis), ${ }^{7}$ provides accessible pathways for the production of some elusive chiral products. ${ }^{8}$ The first examples of asymmetric olefin metathesis were presented by Schrock and Grubbs et al. ${ }^{9}$ using chiral molybdenum complexes. However, the applicability of these complexes was reduced by their sensitivity towards air and water and their low tolerance for a variety of functional groups. More recent studies have produced more stable molybdenum catalysts and significantly advanced the field of molybdenum asymmetric olefin metathesis. ${ }^{10}$ The first examples of chiral ruthenium complexes date back to 2001 and new asymmetric catalysts are still being produced today. ${ }^{11}$ Notwithstanding the efficiency observed for these chiral complexes, ${ }^{12}$ they all require intricate and expensive syntheses of chiral NHC ligands. In light of this, the exploration of straightforward and low cost synthesis protocols of novel functional group tolerant ruthenium pre-catalysts for asymmetric metathesis has remained highly desirable. Moreover, it has been proven over time that there is no "silver bullet"

\footnotetext{
${ }^{a}$ Chemistry Department, Ben-Gurion University of the Negev, Beer-Sheva 84105, Israel. E-mail: lemcoff@bgu.ac.il

${ }^{b}$ School of Chemistry, Tel-Aviv University, Tel-Aviv 69978, Israel

$\dagger$ Electronic supplementary information (ESI) available: Synthesis, characterization and activity of all new complexes, and CIF file for Ru-G. CCDC 1037063. For ESI and crystallographic data in CIF or other electronic format see DOI: 10.1039/ c5cc00052a
}

in olefin metathesis reactions ${ }^{13}$ and different substrates and conditions many times require catalyst optimization. Thus, the ability to produce tunable chiral catalysts is also a sought after goal. Even though in most of the commonly used ruthenium alkylidenes the anionic positions are occupied by chloride ligands, the introduction of different halides and pseudo-halides has been extensively studied in this area. Fine-tuning of the anionic ligands can result in different reactivity and selectivity of the pre-catalysts. ${ }^{14,15}$

Herein, we report on the synthesis of several ruthenium-based olefin metathesis complexes bearing amino acids as chiral anionic ligands and study their efficiency in asymmetric olefin metathesis reactions. The complexes are produced from the most ubiquitous chiral entities in a facile and economical manner, presenting highly tunable options to study this family of asymmetric ruthenium precatalysts.

Amines are strong $\sigma$-donor ligands capable of coordination to the ruthenium center ${ }^{16}$ and thus need to be protected when introduced to ruthenium alkylidene solutions. Accordingly, Boc(tert-butyloxycarbonyl) $N$-substituted amino acids were chosen as starting materials. The protected amino acids were converted to their silver carboxylate salts to ensure complete substitution of both chlorides and 2.1 equivalents of the corresponding silver salts were introduced into a THF solution of a commercially available Hoveyda-Grubbs 2nd generation complex ${ }^{17}$ (Table 1). Interestingly, the use of methylene chloride as the solvent medium led to unsatisfactory results and decomposition of the amino acid ruthenium complexes. Visibly, complexes in methylene chloride solution significantly decomposed after 24 hours, affording an aldehyde by-product and exposing the fragility of these complexes compared to their dichloro counterparts (see ESI $\dagger$ ) ${ }^{18}$ Filtration of the precipitated silver chloride and evaporation of the solvent afforded the products as deep purple solids. Using this straightforward protocol, complexes Ru-G, Ru-A, Ru-L and Ru-F bearing Boc protected glycine, alanine, leucine and phenylalanine, respectively, were prepared. All complexes were obtained in good yields and were duly characterized by NMR spectroscopy, HRMS and specific rotation measurements (Table 1 and ESI $\dagger$ ). As an exception, the use of the Boc-valine and Boc-proline amino acids produced a mixture of the starting material 
Table 1 Synthesis of ruthenium complexes bearing amino acid anionic ligands

\begin{tabular}{|c|c|c|c|c|}
\hline & $\frac{\text { Hoveyda-Grubbs-II }}{\text { THF }}$ & & & $\begin{array}{l}\mathrm{R}=\mathrm{H} \\
\mathrm{R}=\mathrm{CH}_{3} \\
\mathrm{R}=\mathrm{CH}_{2}\left(\mathrm{CH}_{3}\right)_{2} \\
\mathrm{R}=\mathrm{CH}_{2} \mathrm{Ph}^{2}\end{array}$ \\
\hline Complex & R substituent & $\begin{array}{l}\text { Yield } \\
(\%)\end{array}$ & $\begin{array}{l}\text { Benzylidene } \\
\text { hydrogen }^{a}(\mathrm{ppm})\end{array}$ & $\begin{array}{l}\text { Specific } \\
\text { rotation }^{b}\left({ }^{\circ}\right)\end{array}$ \\
\hline $\begin{array}{l}\text { Hoveyda- } \\
\text { Grubbs II }\end{array}$ & - & - & 16.72 & 0.00 \\
\hline Ru-G & $\mathrm{H}$ & 94 & 17.99 & 0.00 \\
\hline Ru-A & $\mathrm{CH}_{3}$ & 95 & 17.62 & +38.3 \\
\hline Ru-L & $\mathrm{CH}_{2}\left(\mathrm{CH}_{3}\right)_{2}$ & 77 & 17.58 & -18.2 \\
\hline $\mathbf{R u}-\mathbf{F}$ & $\mathrm{CH}_{2} \mathrm{Ph}$ & 87 & 17.73 & -37.5 \\
\hline Ru-DA & $\mathrm{CH}_{3}$ & 78 & 17.61 & -38.5 \\
\hline
\end{tabular}

Reaction conditions: THF, $37{ }^{\circ} \mathrm{C}, 3$ hours. ${ }^{a} \mathrm{C}_{6} \mathrm{D}_{6}, 400 \mathrm{MHz}$, for full NMR spectra see ESI. ${ }^{b}$ Specific rotation measured in toluene at $[\alpha]_{\mathrm{D}}^{23}$.

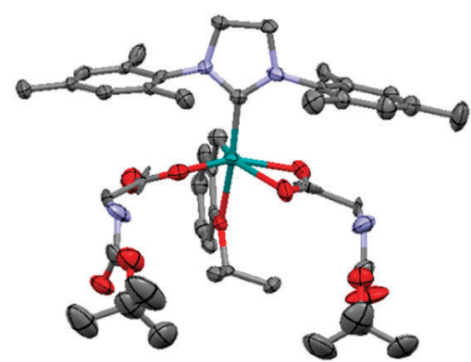

Fig. 1 ORTEP representation (50\% probability ellipsoids) of complex Ru-G. Hydrogen atoms were omitted for clarity.

along with mono- and di-substituted ruthenium complexes, probably due to the higher steric congestion introduced by the isopropyl and pyrrolidine side groups (see ESI $\dagger$ ). Notably, while complex Ru-F has a specific rotation of $-37.5^{\circ}$, the specific rotation of Boc-phenylalanine (Boc-phenylalanine was the only protected amino acid used soluble in toluene) was measured to be $+27.6^{\circ}$, strongly suggesting that optical rotation of polarized light is caused by the complex itself and not by dissociated amino acid in solution. Complex Ru-G was also characterized by single crystal X-ray spectroscopy, showing the typical $\eta^{2}$ hapticity for one of the carboxylate ligands (Fig. 1).

The catalytic efficiency of complexes Ru-G, Ru-A, Ru-L and Ru-F was tested in ARCM and AROCM benchmark reactions. ${ }^{7 b}$ The initial results showed excellent conversions for AROCM of norbornene 1 and ARCM of triene 2 (Table 2), but with very poor enantioselectivities. Alanine complex Ru-A afforded the highest enantioselectivity with just $20 \% e e$. Lowering the temperature to $0{ }^{\circ} \mathrm{C}$ improved the ee to $27 \%$, yet significantly reduced the conversion.

An advantage of this methodology is that amino acids are readily available in their mirror-image forms and thus hold a valuable key for major product selection. To demonstrate the ease with which a specific enantiomer may be obtained, readily available $\mathrm{N}$-Boc protected D-alanine was used to synthesize Ru-DA under the same conditions described previously. Ru-DA displayed NMR spectra identical to those of Ru-A and opposite specific rotation (Table 1). As expected, asymmetric ring closing of triene
Table 2 AROCM and ARCM with chiral Ru pre-catalysts

\begin{tabular}{|c|c|c|c|c|c|}
\hline Entry & Substrate & Product & Catalyst & $\begin{array}{l}\text { Conversion }^{a} \\
{[\%]}\end{array}$ & $\begin{array}{l}e e^{b} \\
{[\%]}\end{array}$ \\
\hline 1 & 1 & 3 & Hoveyda-Grubbs II & 100 & 0 \\
\hline 2 & & & Ru-G & 100 & 0 \\
\hline 3 & & & $\mathbf{R u}-\mathbf{A}$ & 100 & 4 \\
\hline 4 & & & Ru-DA & 100 & 4 \\
\hline 5 & & & $\mathbf{R u}-\mathbf{F}$ & 100 & 4 \\
\hline 6 & 2 & 4 & Hoveyda-Grubbs II ${ }^{c}$ & 100 & 0 \\
\hline 7 & & & Ru-G & 83 & 0 \\
\hline 8 & & & $\mathbf{R u}-\mathbf{F}^{d}$ & 93 & 0 \\
\hline 9 & & & Ru-L & 100 & 12 \\
\hline 10 & & & Ru-A & 100 & 20 \\
\hline 11 & & & Ru-DA & 100 & 20 \\
\hline
\end{tabular}

AROCM conditions: 8.0 mol\% catalyst loadings, 13.0 equivalents of styrene, $55 \mathrm{mM}$ substrate in THF, $37{ }^{\circ} \mathrm{C}, 2$ hours. ARCM conditions: $8.0 \mathrm{~mol} \%$ catalyst loadings, $55 \mathrm{mM}$ substrate in THF, $37^{\circ} \mathrm{C}, 2$ hours. ${ }^{a}$ Conversion was monitored by GC-MS. ${ }^{b} e e$ was determined by HPLC (Reprosil chiral-NR, $8 \mu \mathrm{m}, 150 \times 4.5 \mathrm{~mm}$ ). ${ }^{c} 2.5 \mathrm{~mol} \%{ }^{d} 7.0 \mathrm{~mol} \%$.

2 catalyzed by Ru-DA readily provided excess of the opposite enantiomeric product to that obtained by the use of $\mathbf{R u}-\mathbf{A}$ (Table 2, entries 10 and 11) as shown by the different chiral HPLC chromatograms (see ESI $\dagger$ ). For both metathesis reactions we expected increased $e e$ as the size of the substituent of the amino acid increased (i.e. highest $e e$ for Ru-F); yet Table 2 displays the opposite trend. This seems to imply that a fine balance between steric hindrance and electronic effects is required in order to obtain satisfactory asymmetric induction. While greater steric stress in the asymmetric environment could contribute to higher enantioselectivity, we hypothesized that steric hindrance may also lead to enhanced ligand dissociation, leading to a detrimental outcome. Ligands at the anionic positions in Hoveyda-Grubbs type complexes are known for their lability and dynamic nature, and were shown in solution to dissociate as a part of a degenerate ligand exchange. ${ }^{19}$ Both reduced complex stability and ligand dissociation may be the cause for the low enantioselectivities observed in Table 2.

In order to study the specific lability of the amino acid ligands used, disproportionation of Ru-A and Ru-F in the presence of Boc-glycine silver salt (Scheme 1) was monitored by ${ }^{1} \mathrm{H}-\mathrm{NMR}$. Qualitative inspection of the carbene region disclosed a faster exchange of the Boc-phenylalanine ligand by the Boc-glycine ligand, compared to the Boc-alanine ligand. This observation falls in line with our assumption that greater steric stress in the system facilitates ligand dissociation. Since the chiral induction in our system originates from the anionic ligand, greater ligand

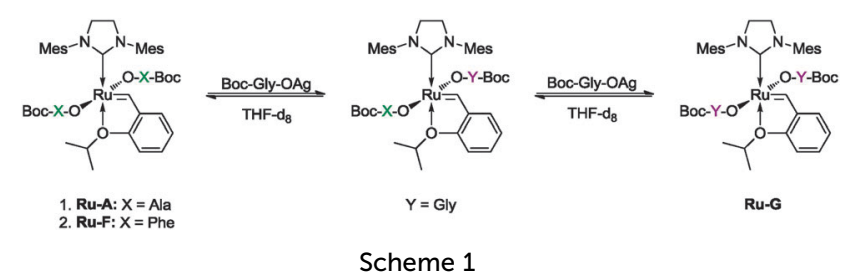


Table 3 Solvent effect on ARCM of triene $\mathbf{2}$ with Ru-A as a pre-catalyst

\begin{tabular}{lllll}
\hline Entry & Solvent & Additive $^{a}$ & Conversion $^{b}[\%]$ & $e e^{c}[\%]$ \\
\hline 1 & THF & - & 100 & 20 \\
2 & THF & Ala-OAg & $89^{d}$ & 34 \\
3 & Benzene & - & $92^{d}$ & 44 \\
4 & Benzene & Ala-OAg & $63^{d}$ & 56
\end{tabular}

ARCM conditions: $8.0 \mathrm{~mol} \%$ catalyst loadings, $55 \mathrm{mM}$ substrate in solvent, $37^{\circ} \mathrm{C}, 2$ hours. ${ }^{a} 40 \mathrm{~mol} \%$ with respect to Ru-A. ${ }^{b}$ Conversion was monitored by GC-MS. ${ }^{c} e e$ was determined by HPLC (Reprosil chiral-NR, $8 \mu \mathrm{m}, 150 \times$ $4.5 \mathrm{~mm}) .{ }^{d}$ Accompanied by cycloisomerization products. ${ }^{11 j, 21}$

dissociation can severely hamper the enantioselectivity obtained. In order to achieve enantioselectivity without a chiral NHC ligand, it is reasonable to assume that both chiral anionic ligands must be associated with the ruthenium center during the stereochemistry determining step. In related work, Grela et al. probed the asymmetric efficiency of a chiral at metal ruthenium pre-catalyst. ${ }^{20}$ The complex, bearing two, not labile, achiral anionic ligands (trifluoroacetate and iodide ligands), was isolated in its optically pure form. Lack of enantioselectivity in this system was explained by a fast racemization mechanism of the propagating species and underlined the need for a permanent asymmetric induction derived directly from the ligands for asymmetric olefin metathesis.

To further support the hypothesis that ligand lability was hampering enantioselectivity, an ARCM reaction catalyzed by Ru-A was carried out in the presence of excess of Boc-alanine silver salt (Table 3, entries 1 and 2). To our satisfaction, an increase in $e e$ from $20 \%$ to $34 \%$ was observed by this protocol (alongside increased isomerization of the substrate ${ }^{11 j, 21}$ ). Continuing with this line of reasoning, the reaction was repeated in a less polar solvent to inhibit ligand dissociation. Indeed, changing the solvent to benzene $\left(E_{\mathrm{T}}^{\mathrm{N}} \text { benzene }=0.111 ; E_{\mathrm{T}}^{\mathrm{N}} \mathrm{THF}=0.207\right)^{22}$ increased the $e e$ to $44 \%$ (Table 3 , entry 3 ), while the addition of excess of Boc-alanine silver salt in this solvent afforded an enantiomeric excess value of $56 \%$ (Table 3, entry 4). Thus, just by changing the solvent polarity and adding excess anionic ligand, the enantioselectivity could be steadily increased from $20 \%$ to $56 \%$. Unfortunately, further reduction of solvent polarity by using benzene/hexane $1: 1$ and $2: 1$ mixtures led to extremely low conversions $\left(E_{\mathrm{T}}^{\mathrm{N}}\right.$ hexane $\left.=0.009\right)$. The above experiments clearly confirm the profound impact the dynamic nature of the anionic ligand has on the course of this reaction and dictates the path for future optimization of this promising protocol in asymmetric olefin metathesis.

In conclusion, five ruthenium complexes bearing amino acids as anionic ligands were synthesized and characterized. The chiral complexes were probed in asymmetric ring closing metathesis and asymmetric ring opening cross-metathesis, showing high conversions, albeit with poor enantioselectivity. Notably, the use of Boc-D-alanine as the anionic ligand for the ruthenium complex readily provided excess of the opposite enantiomer product in ARCM. To the best of our knowledge, this series represents the first chiral ruthenium alkylidenes not containing asymmetric NHC ligands that display enantioselectivity in olefin metathesis reactions. Surprisingly, the least sterically hindered chiral ligand, Boc-alanine, was the one to afford the highest ee suggesting that lability of the amino acid ligands plays an important role in the loss of enantioselectivity. This hypothesis was supported by the fact that Boc-phenylalanine was found to exchange more rapidly than Boc-alanine, and that the addition of excess Boc-alanine promptly improved the enatioselectivity for ARCM. Moreover, changing the reaction medium to a less polar solvent also had a beneficial effect on the enantioselectivity, raising the $e e$ over $50 \%$. The approach presented herein provides facile synthesis protocols using readily available commercial starting materials, easy access to a specific enantiomeric product by a simple choice of the appropriate amino acid symmetry and an extensive chiral pool of readily available amino acid or peptide ligands to study. The introduction of dipeptides and alternative chiral anionic ligands that may strengthen the binding to the ruthenium center ${ }^{20}$ opens a window to combinatorial studies in this area and is currently being probed to improve these promising first results.

\section{Notes and references}

1 (a) Y. Chauvin, Angew. Chem., Int. Ed., 2006, 45, 3740; (b) R. R. Schrock, Angew. Chem., Int. Ed., 2006, 45, 3748; (c) R. H. Grubbs, Angew. Chem., Int. Ed., 2006, 45, 3760.

2 (a) Handbook of Metathesis, ed. R. H. Grubbs, Wiley-VCH, Weinheim, Germany, 2003; (b) Olefin Metathesis: Theory and Practice, ed. K. Grela, John Wiley \& Sons, 2014; (c) D. J. Nelson, S. Manzini, C. A. UrbinaBlanco and S. P. Nolan, Chem. Commun., 2014, 50, 10355.

3 (a) S. J. Meek, R. V. O'Brien, J. Llaveria, R. R. Schrock and A. H. Hoveyda, Nature, 2011, 471, 461; (b) A. Fürstner, Science, 2013, 341, 1229713; (c) L. E. Rosebrugh, M. B. Herbert, V. M. Marx, B. K. Keitz and R. H. Grubbs, J. Am. Chem. Soc., 2013, 135, 1276; (d) R. K. M. Khan, S. Torker and A. H. Hoveyda, J. Am. Chem. Soc., 2013, 135, 10258; (e) G. Occhipinti, F. R. Hansen, K. W. Törnroos and V. R. Jensen, J. Am. Chem. Soc., 2013, 135, 3331; $(f)$ S. Shahane, C. Bruneau and C. Fischmeister, ChemCatChem, 2013, 5, 3436; $(g)$ G. Occhipinti, V. Koudriavtsev, K. W. Törnroos and V. R. Jensen, Dalton Trans., 2014, 43, 11106.

4 (a) M. Barbasiewicz, A. Szadkowska, R. Bujok and K. Grela, Organometallics, 2006, 25, 3599; (b) A. Szadkowska and K. Grela, Curr. Org. Chem., 2008, 12, 1631; (c) A. Ben-Asuly, E. Tzur, C. E. Diesendruck, M. Sigalov, I. Goldberg and N. G. Lemcoff, Organometallics, 2008, 27, 811; (d) D. Wang, K. Wurst, W. Knolle, U. Decker, L. Prager, S. Naumov and M. R. Buchmeiser, Angew. Chem., Int. Ed., 2008, 47, 3267; (e) A. Piermattei, S. Karthikeyan and R. P. Sijbesma, Nat. Chem., 2009, 1, 133; $(f)$ S. Monsaert, A. Lozano Vila, R. Drozdzak, P. Van Der Voort and F. Verpoort, Chem. Soc. Rev., 2009, 38, 3360; $(g)$ Y. Vidavsky and N. G. Lemcoff, Beilstein J. Org. Chem., 2010, 6, 1106; (h) Y. Ginzburg, A. Anaby, Y. Vidavsky, C. E. Diesendruck, A. Ben-Asuly, I. Goldberg and N. G. Lemcoff, Organometallics, 2011, 30, 3430; (i) Y. Vidavsky, A. Anaby and N. G. Lemcoff, Dalton Trans., 2012, 41, 32.

5 (a) I. C. Stewart, C. J. Douglas and R. H. Grubbs, Org. Lett., 2008, 10, 441; (b) T. Vorfalt, S. Leuthäußer and H. Plenio, Angew. Chem., Int. Ed., 2009, 48, 5191; (c) T. E. Schmid, X. Bantreil, C. A. Citadelle, A. M. Slawin and C. S. Cazin, Chem. Commun., 2011, 47, 7060; (d) Z. Wang, W. R. Jackson and A. J. Robinson, Org. Lett., 2013, 15, 3006.

6 (a) D. Burtscher and K. Grela, Angew. Chem., Int. Ed., 2009, 48, 442; (b) J. Tomasek and J. Schatz, Green Chem., 2013, 15, 2317.

7 (a) R. R. Schrock and A. H. Hoveyda, Chem. - Eur. J., 2001, 7, 945; (b) S. Kress and S. Blechert, Chem. Soc. Rev., 2012, 41, 4389; (c) C. Deraedt, M. d'Halluin and D. Astruc, Eur. J. Inorg. Chem., 2013, 4881.

8 (a) K. C. Nicolaou, P. G. Bulger and D. Sarlah, Angew. Chem., Int. Ed., 2005, 44, 4490; (b) S. J. Malcolmson, S. J. Meek, E. S. Sattely, R. R. Schrock and A. H. Hoveyda, Nature, 2008, 456, 933; (c) A. H. Hoveyda, S. J. Malcolmson, S. J. Meek and A. R. Zhugralin, Angew. Chem., Int. Ed., 2010, 49, 34.

9 (a) K. M. Totland, T. J. Boyd, G. G. Lavoie, W. Davis and R. R. Schrock, Macromolecules, 1996, 29, 6114; (b) O. Fujimura and R. H. Grubbs, J. Am. Chem. Soc., 1996, 118, 2499.

10 (a) R. R. Schrock, J. Mol. Catal. A: Chem., 2004, 213, 21; (b) S. J. Malcolmson, S. J. Meek, E. S. Sattely, R. R. Schrock and A. H. Hoveyda, Nature, 2008, 456, 933; (c) J. Heppekausen and A. Fürstner, Angew. Chem., Int. Ed., 2011, 50, 7829; (d) M. Ogasawara, W.-Y. Wu, S. Arae, 
S. Watanabe, T. Morita, T. Takahashi and K. Kamikawa, Angew. Chem., Int. Ed., 2012, 51, 2951; (e) M. Yu, I. Ibrahem, M. Hasegawa, R. R. Schrock and A. H. Hoveyda, J. Am. Chem. Soc., 2012, 134, 2788; $(f)$ M. Ogasawara, S. Arae, S. Watanabe, K. Nakajima and T. Takahashi, Chem. - Eur. J., 2013, 19, 4151.

11 For reviews on chiral NHC-metal complexes see: (a) J. Tornatzky, A. Kannenberg and S. Blechert, Dalton Trans., 2012, 41, 8215; (b) F. Wang, L.-J. Liu, W. Wang, W. S. Li and M. Shi, Coord. Chem. Rev., 2012, 256, 804. For selected examples see: $(c)$ T. J. Seiders, D. W. Ward and R. H. Grubbs, Org. Lett., 2001, 3, 3225; (d) J. J. Van Veldhuizen, S. B. Garber, J. S. Kingsbury and A. H. Hoveyda, J. Am. Chem. Soc., 2002, 124, 4954; (e) J. J. Van Veldhuizen, D. G. Gillingham, S. B. Garber, O. Kataoka and A. H. Hoveyda, J. Am. Chem. Soc., 2003, 125, 12502; $(f)$ J. J. Van Veldhuizen, J. E. Campbell, R. E. Giudici and A. H. Hoveyda, J. Am. Chem. Soc., 2005, 127, 6877; $(g)$ T. W. Funk, J. M. Berlin and R. H. Grubbs, J. Am. Chem. Soc., 2006, 128, 1840; (h) J. M. Berlin, S. D. Goldberg and R. H. Grubbs, Angew. Chem., Int. Ed., 2006, 45, 7591; (i) P.-A. Fournier and S. K. Collins, Organometallics, 2007, 26, 2945; $(j)$ F. Grisi, C. Costabile, E. Gallo, A. Mariconda, C. Tedesco and P. Longo, Organometallics, 2008, 27, 4649; ( $k$ ) S. Tiede, A. Berger, D. Schlesiger, D. Rost, A. Lühl and S. Blechert, Angew. Chem., Int. Ed., 2010, 49, 3972; $(l)$ B. Stenne, J. Timperio, J. Savoie, T. Dudding and S. K. Collins, Org. Lett., 2010, 12, 2032; $(m)$ A. Kannenberg, D. Rost, S. Eibauer, S. Tiede and S. Blechert, Angew. Chem., Int. Ed., 2011, 50, 3299; (n) R. K. M. Khan, A. R. Zhugralin, S. Torker, R. V. O'Brien, P. J. Lombardi and A. H. Hoveyda, J. Am. Chem. Soc., 2012, 134, 12438; (o) J. Hartung, P. K. Dornan and R. H. Grubbs, J. Am. Chem. Soc., 2014, 136, 13029.

12 For interpretations on the origin of enantioselectivity of chiral NHC-ruthenium complexes see: $(a)$ C. Costabile and L. Cavallo, J. Am. Chem. Soc., 2004, 126, 9592; (b) C. Costabile, A. Mariconda,
L. Cavallo, P. Longo, V. Bertolasi, F. Ragone and F. Grisi, Chem. - Eur. J., 2011, 17, 8618.

13 A. Szadkowska, C. Samojlowicz and K. Grela, Pure Appl. Chem., 2011, 83, 553.

14 E. B. Anderson and M. R. Buchmeiser, Synlett, 2012, 185.

15 S. Torker, R. K. M. Khan and A. H. Hoveyda, J. Am. Chem. Soc., 2014, 136, 3439.

16 (a) G. O. Wilson, K. A. Porter, H. Weissman, S. R. White, N. R. Sottos and J. S. Moore, Adv. Synth. Catal., 2009, 351, 1817; (b) J. A. M. Lummiss, B. J. Ireland, J. M. Sommers and D. E. Fogg, ChemCatChem, 2014, 6, 459.

17 (a) S. B. Garber, J. S. Kingsbury, B. L. Gray and A. H. Hoveyda, J. Am. Chem. Soc., 2000, 122, 8168; (b) S. Gessler, S. Randl and S. Blechert, Tetrahedron Lett., 2000, 41, 9973.

18 K. Vehlow, S. Maechling, K. Köhler and S. Blechert, Tetrahedron Lett., 2006, 47, 8617.

19 (a) K. Tanaka, V. P. W. Böhm, D. Chadwick, M. Roeper and D. C. Braddock, Organometallics, 2006, 25, 5696; (b) O. Songis, A. M. Z. Slawin and C. S. J. Cazin, Chem. Commun., 2012, 48, 1266; (c) T. G. Larocque, A. C. Badaj and G. G. Lavoie, Dalton Trans., 2013, 42, 14955.

20 R. Gawin and K. Grela, Eur. J. Inorg. Chem., 2012, 1477.

21 S. H. Hong, D. P. Sanders, C. W. Lee and R. H. Grubbs, J. Am. Chem. Soc., 2005, 127, 17160.

22 The $E_{\mathrm{T}}^{\mathrm{N}}$ value (Reichardt parameter) is a widely used scale for solvent polarity. The $E_{\mathrm{T}}^{\mathrm{N}}$ scale is proportional to the $E_{\mathrm{T}}(30)$ values based on the solvatochromic properties of a pyridinium $N$-phenolate betaine dye as a probe molecule. The $E_{\mathrm{T}}^{\mathrm{N}}$ scale is normalized by adopting the value of 1 for water and 0 for tetramethylsilane. See, C. Reichardt, Chem. Rev., 1994, 94, 2319. 